\title{
SUBMISSION OF ALLEGED AND UNLIVED SYSTEMS TO PROVIDE HEAT TRANSFER EFFICIENCY
}

\begin{abstract}
A. Fernandes, ABSTRACT
G. D. Souza,

L. Dias,

and L. F. S. Silva

Faculdade Integrada Einstein de Limeira Departamento de Engenharia Mecânica Vila Queiroz

CP. 1018, Limeira, São Paulo, Brasil adeiltonfernandes7@gmail.com guilherme.dsouzza@gmail.com laryssaaa.d@gmail.com fernandohuck@hotmail.com
\end{abstract}

Received: January 10, 2020 Revised: February 21, 2020 Accepted: August 28, 2020

Keywords: heat transfer; thermostats; finished and non-finished system

\section{NOMENCLATURE}

\section{A Surface Area}

C Fluid specific heat at constant pressure, J / (kg.K)

${ }^{\circ} \mathrm{C} \quad$ Celsius Degrees (Temperature)

F Fins

J Mechanical Energy Measurement Unit

K Thermal conductivity

K Type K Thermocouple

K Kelvin Temperature Measurement Unit

L1 / L2 / L3 Material thickness measurements

M Mass Unit

M Metro unit of measure

NF Not Fins

Q Amount of Heat Transferred

$\mathrm{Q}$ Unit of measure for heat flow

$\mathrm{R} \quad$ Thermal Resistance

S Sample

$\mathrm{T}$ Temperature

V Volts

W Watts Power Unit

T1 Thermopars - Channel 1

T2 Thermopars - Channel 2

T3 Thermopars - Channel 3

T4 Thermopars - Channel 4

T5 Thermopars - Channel 5

T6 Thermopars - Channel 6

T7 Thermopars - Channel 7

T8 Thermopars - Channel 8

\section{Greek symbols}

$\Delta \mathrm{Q} / \Delta \mathrm{t} \quad$ Heat flow rate;

$\Delta \mathrm{T} \quad$ variation in temperature;

$\mu \quad$ Micron

\section{Subscripts}

Kcal Kilocalorie

$\mathrm{Kg} \quad$ Unit of mass measurement

M10 Metric Screw System Standard

MM Unit of measurement for length Millimeters

SAE Steel Standard (Society of Automotive Engineers - USA)

TC-08 Data Intake Plate Model

USB Universal Serial Bus

VGA Video Graphics Array Standard

\section{INTRODUCTION}

The empirical test related to the randomized and non-allocated systems is based on a process of heat transfer generated by a resistance and transferred to the dummy and non-allocated heads, by a convection process where the heat was insulated by a steel-built equipment and insulating blanket. Basically, the float head is characterized by heat transfer by conduction, where the fins have as main characteristics increase the heat transfer surface, where it increases its cooling efficiency in a certain material. 


\section{THEORY}

The heat transfer explains how the heat is propagated and the rates that occur, that is, the transfer modes. This process happens when two or more bodies that are at different temperatures are placed in contact, causing the energy of one body to be transferred to another.

Heat is considered a form of energy that spontaneously transmits from one body to another when among them there is a temperature difference.

The difference or temperature gradient between bodies results in the establishment of an energy flow in the form of heat, which always flows from the body warmer to the less heated. Possible modes for occurrence are: Conduction, convection and Radiation (SOUZA, 2016).

Conduction heat transfer: a basic relationship for conduction heat transmission was proposed by the French scientist J. B. J. Fourier in 1822.

Conduction is a process whereby the heat flux from one high temperature region to another lower temperature is within a medium (solid, liquid or gas) or between different media in direct physical contact.

Conduction is a mechanism by which heat can flow into opaque solids. The conduction is also important in the fluids but, in the non solid media it is usually combined with the convection and in some cases also as radiation (KREITH, 1969).

Convection heat transfer: convection is a process of energy transport through the combined action of heat conduction, energy storage and mixing motion. Convection is most important as a mechanism of energy transfer between a solid surface and a liquid or gas.

Two examples are the refrigerator and the water heater. A mathematical theory of heat convection is quite complex. There is no simple equation for convection as there is for conduction. This is due to the fact that heat lost or gained by a surface and a temperature in contact with a fluid at another temperature, depends on several factors, such as whether the surface is flat or curved, whether the surface is horizontal or vertical, if fluid is flowing. Surface contact is a liquid or gas, density, viscosity, specific heat, thermal conductivity of the fluid, among others (GASPAR, 2002).

The convection heat transmission is classified according to the flow motivation mode, in natural convection and forced convection (KREITH, 1969).

Natural Convection when the mixing movement takes place, merely as a result of the density differences caused by the temperature gradients, we speak of natural or free convection (KREITH, 1969).

Forced Convection when the mixing movement is induced by some external agent, such as a pump or a fan, the process is called forced convection (KREITH, 1969).

Radiation heat transfer: radiation is a process by which heat flows from a body at high temperature to a lower one, when they are separated in space, even though there is a vacuum between them.

The term radiation is applied to all kinds of electromagnetic wave phenomena, but in heat transmission only the phenomena that result from temperature differences and can carry energy through space are of interest. This energy is called radiant heat.

According to teacher Frank Kreith (1969) radiant heat is emitted by a body in the form of quantum energy impulses.

Fins: looking at the heat transfer modes, it can be seen that any change in parameters results in changes in the amount of heat exchange and the larger the exposed area, the higher the transfer rate.

The concept of fins is based on the increase of the surface area that is, extended surfaces with greater exposure area with the function of maximizing the transfer rates without the need to change the variables. There are two types of fins: internal and external. In addition, they can be cut into helices, notches, studded, wavy, among others (SOUZA, 2016).

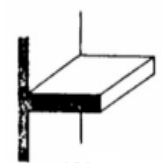

(A)

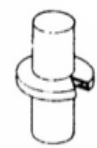

(E)

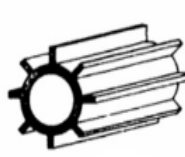

(B)

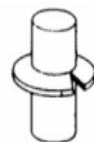

(F)

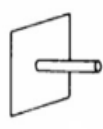

(G)

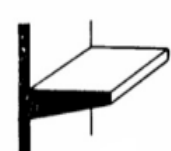

(C)

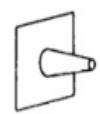

(H)

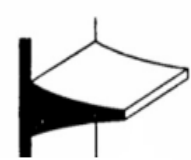

(D)

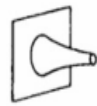

(l)
Figure 1. Different types of finned surfaces, according to Kreith and Bohn. (A) longitudinal fin of rectangular profile; (B) cylindrical tube with rectangular profile fins; $(\mathrm{C})$ longitudinal fin of trapezoidal profile; (D) longitudinal fin of parabolic profile; (E) cylindrical tube equipped with radial fin;

(F) cylindrical tube fitted with radial fin with truncated conical profile; $(\mathrm{G})$ cylindrical pin; $(\mathrm{H})$ truncated tapered pin; (I) parabolic pin.

Thermocouples are simple, robust temperature sensors that are very reliable in their measurements and inexpensive. Being widely used in various temperature measurement processes, the thermocouple consists of two distinct metals joined at one end. When there is a temperature difference between the joined end and the free ends, there is a potential difference that can be measured by a voltmeter, different thermocouple types have different curve types, and this is a curve that shows the potential difference in relation to temperature change.

The thermocouple type $\mathrm{K}$ was used in the experiment and is one of the most used, has a low 
cost because of its popularity are available various probes.

They even cover temperatures ranging from $200^{\circ} \mathrm{C}$ to $1370^{\circ} \mathrm{C}$, with a sensitivity of approximately $41 \mu \mathrm{V} /{ }^{\circ} \mathrm{C}$ (MELO, 2018).

\section{EXPERIMENTS}

\section{Materials Used:}

- 1 Thermostat from 0 to $120^{\circ} \mathrm{C}$.

- Case made of SAE 1020 steel

- Insulation with $10 \mathrm{~mm}$ thickness (Ceramic Fiber) at the base and sides of the box.

- High temperature silicone

- 1 3000W air resistance 220V - (Width 50mm X Length 370mm X Height 20mm).

- 8 Type K Thermocouples.

- 1 TC-08 Data Intake Card - PICO TECH brand with VGA and USB communication.

- 1 computer for data analysis.

- $2110 \mathrm{~V}$ fans.

- 1 Halved (Aluminum) Spindle Head secured by 4 M10 screws.

\section{DESCRIPTION OF THE ASSEMBLY}

Inside a 2 mm thick SAE 1020 carbon steel case insulated with ceramic fiber at the base and sides, a $3000 \mathrm{~W}$ power and $220 \mathrm{~V}$ resistance was achieved.

Figure 2. Resistant housing interior.

At the top of the housing were placed two halves of aluminum screw heads fixed by 4 M10 screws each. In addition, two fans were installed on a ceramic behind each block, so that when connected they would refrigerate them.

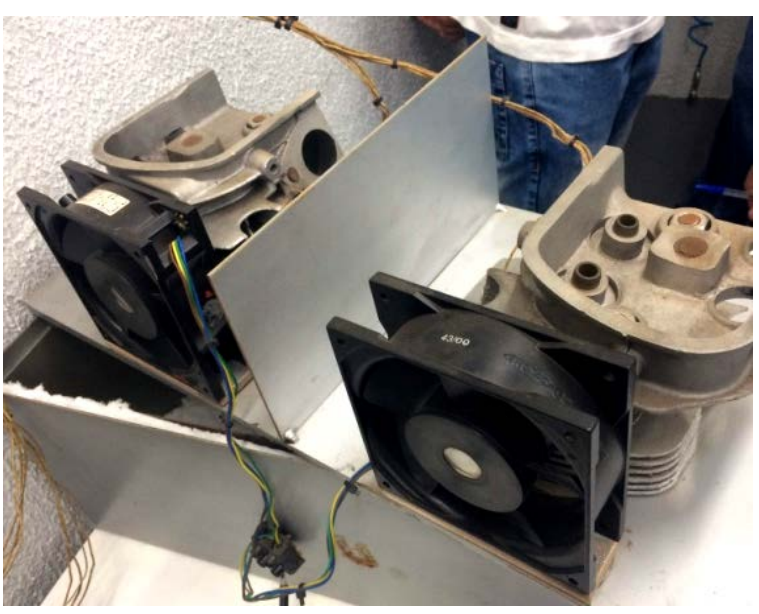

Figure 3. Head and fans.

Four K-type thermocouples were attached to each head with high temperature silicone, totaling 8 thermocouples to collect the temperatures of the experiment.

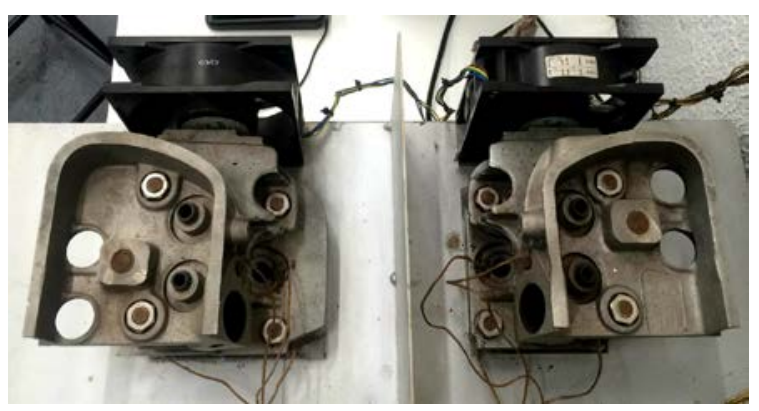

Figure 4. Thermocouple fixation.

In the front of the box, a thermostat with temperature from 0 to $120^{\circ} \mathrm{C}$ was installed so that it could regulate the temperature of the resistance.

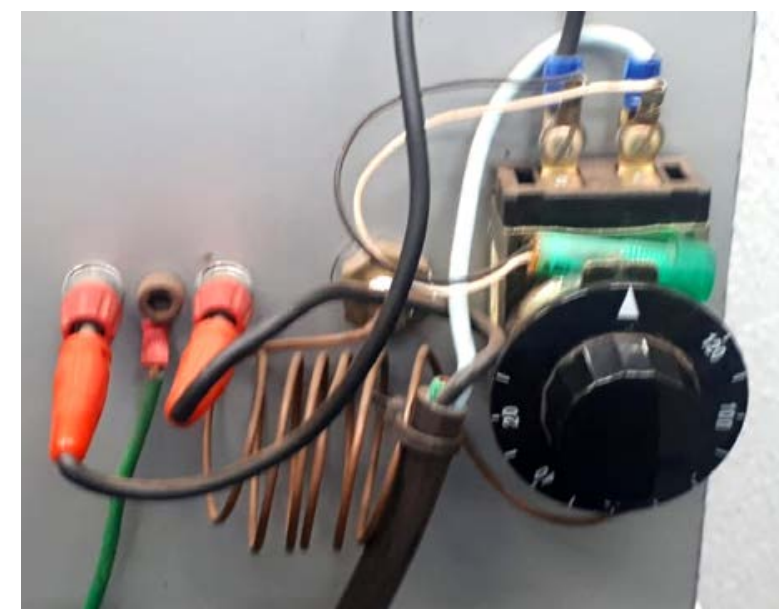

Figure 5. Thermostat fixation 0 to $120^{\circ} \mathrm{C}$.

Next to the box, a TC-08 - PICO TECH input card with VGA and USB communication was placed so that the thermocouples transmit information to the 
same one that forwards to the computer with the data converted from millivolts to binary signal.

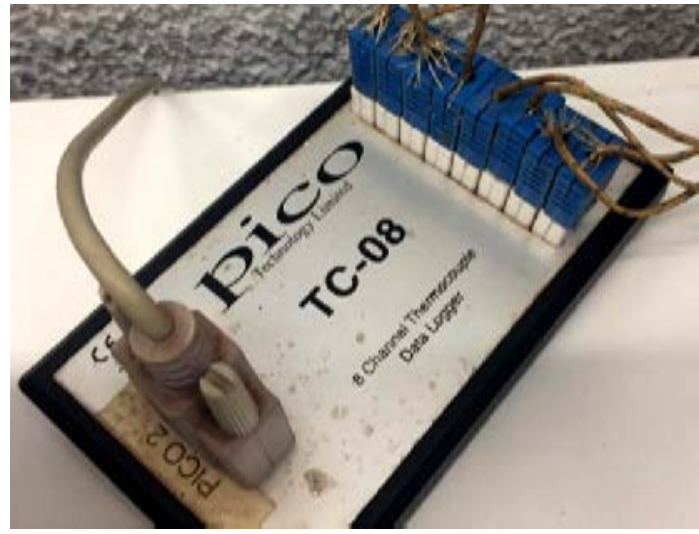

Figure 6. Data Intake Card.

For the analysis and understanding of the information, after receiving the data from the plate, computer software was used, which converts the analysis in degrees Celsius $\left({ }^{\circ} \mathrm{C}\right)$ and indicates each measured channel.

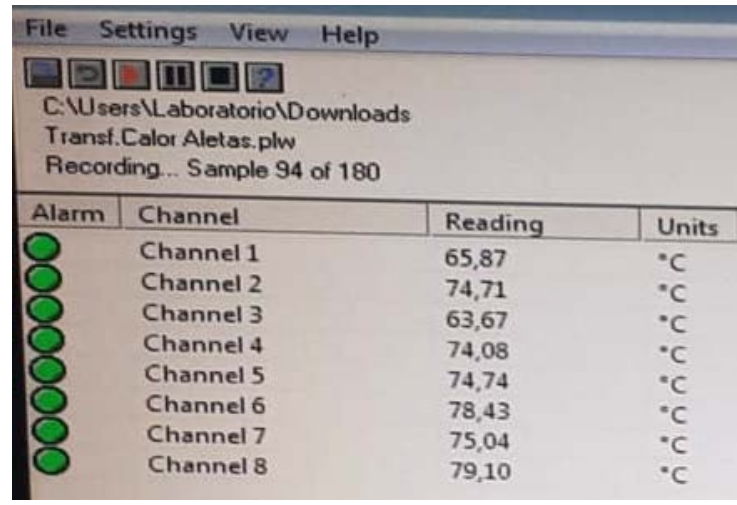

Figure 7. Analysis Software.

\section{DESCRIPTION OF THE EXPERIMENT}

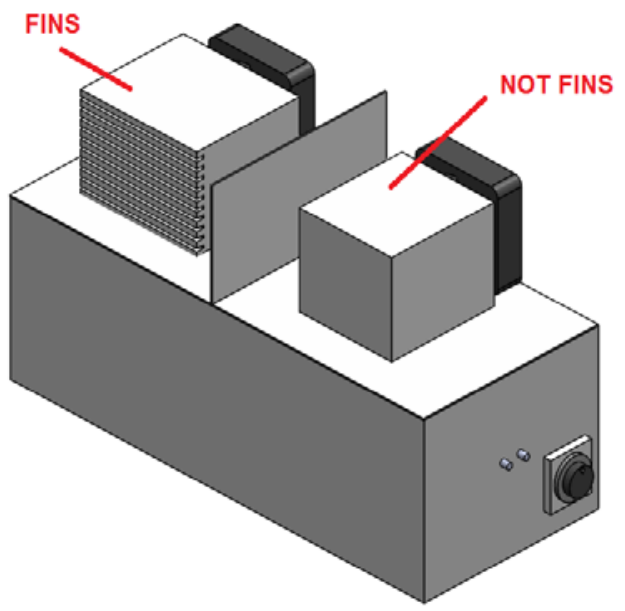

Figure 8. Transmission Box Schematic Design.
The thermocouples were positioned in the same locations and numbered: Channel 1 to 4 NOT FINS and Channel 5 to 8 FINS.

After being glued to the head, the thermocouples were connected to the TC-08 Data Intake Plate - PICO TECH mark for the conversion of the information to the program.

In the program, filters and 8 type $\mathrm{K}$ thermocouples were defined and enabled.

The data collection system was programmed to present an analysis every 10 seconds, that is, a temperature, totaling 180 data.

Started the test was verified temperature of $27^{\circ} \mathrm{C}$ which is considered ambient.

After the start, there was a small temperature difference in the thermocouples due to several factors such as adjustments, position, environment and equipment life.

Following the data collection, a problem was detected between samples 13 and 23, where the temperature rose rapidly near $300^{\circ} \mathrm{C}$. The cause of this would be due to the magnetic field of the resistance, which was resolved by grounding the box.

Continuing the collection, it was found that upon reaching a stabilized temperature, average of 80 ${ }^{\circ} \mathrm{C}$, in the case of sample 84 , the fans turned on, thus performing forced convective cooling.

After the fans were turned on, the data were analyzed until reaching the sample 180 where the experiment ended.

\section{RESULTS AND DISCUSSION}

To calculate the thermal flow through a flat wall, the equations were determined using Fourier's law, it is given by the equation:

$$
\dot{q}=\frac{(\Delta T)_{\text {total }}}{R_{t}}=\frac{T_{1}-T_{4}}{R_{t}}=\frac{T_{1}-T_{4}}{\frac{L_{1}}{k_{1} \cdot A}+\frac{L_{2}}{k_{2} \cdot A}+\frac{L_{3}}{k_{3} \cdot A}}
$$

Equation (1) is used when you have two or more walls, thus showing the calculation of heat flow transferred in the insulation walls of the box, where $\mathrm{L}$ would be the wall thickness, Rt the thermal resistance which is the solution of $\mathrm{L}$ divided by $\mathrm{K}$ which is thermal conductivity multiplied by $\mathrm{A}$ which is the area of the wall, T1 the internal temperature of the box and T4 the external, thus being able to calculate the rate of heat transfer from the internal to the external. (Incropera, 2008).

The calculation of the insulation box was done with Eq. (1), which has two layers of steel plate with a layer of ceramic fiber in the middle, as shown in figure 9 .

$$
\begin{aligned}
& \mathrm{L} 1=0.002 \mathrm{~m}-\text { steel }-\mathrm{K}=51.9 \mathrm{~W} / \mathrm{m} . \mathrm{k} \\
& \mathrm{L} 2=0.01 \mathrm{~m}-\text { Ceramic Fiber }-\mathrm{K}=0.46 \mathrm{~W} / \mathrm{m} . \mathrm{k} \\
& \mathrm{L} 3=0.002 \mathrm{~m}-\text { steel }-\mathrm{K}=51.9 \mathrm{~W} / \mathrm{m} . \mathrm{k}
\end{aligned}
$$


$\mathrm{T} 1=120^{\circ} \mathrm{C}-393 \mathrm{~K}$ (Case Inside) $\mathrm{T} 4=27^{\circ} \mathrm{C}-300 \mathrm{~K}$ (Environment) $\mathrm{A}=0.49 \mathrm{~m}$

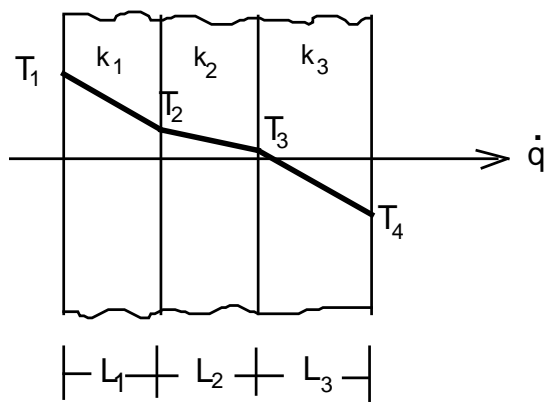

Figure 9. Heat flow.

$$
\begin{aligned}
& \mathrm{q}=\frac{(\Delta \mathrm{T})_{\text {total }}}{\mathrm{R}_{\mathrm{t}}}=\frac{\mathrm{T}_{1}-\mathrm{T}_{4}}{\mathrm{R}_{\mathrm{t}}} \Rightarrow \\
& \mathrm{q}=\frac{\mathrm{T}_{1}-\mathrm{T}_{4}}{\frac{\mathrm{L}_{1}}{\mathrm{k}_{1} * \mathrm{~A}}+\frac{\mathrm{L}_{2}}{\mathrm{k}_{2} * \mathrm{~A}}+\frac{\mathrm{L}_{3}}{\mathrm{k}_{3} * \mathrm{~A}}} \Rightarrow
\end{aligned}
$$

$$
q=\frac{\frac{0.002}{51.9 * 0.49}+\frac{0.01}{0.46 * 0.49}+\frac{0.002}{51.9 * 0.49}}{q=2088.82 \mathrm{Kal} / \mathrm{h}}
$$

For the calculation of a wall the following equation is used:

$$
\dot{\mathrm{q}}=\frac{\mathrm{k} \cdot \mathrm{A}}{\mathrm{L}} \cdot\left(\mathrm{T}_{1}-\mathrm{T}_{2}\right)
$$

In equation (3) the calculation of the heat flow transferred in the lid of the box, where $\mathrm{L}$ would be the thickness of the lid, $\mathrm{K}$ is the thermal conductivity of the material, A is the area of the lid, T1 the internal temperature of the box and $\mathrm{T} 2$ a thus being able to calculate the heat transfer rate from internal to external. (Incropera, 2008).

Next we will show the calculation of the steel cover, using Eq. (3):

$$
\begin{gathered}
\mathrm{L}=0.002 \mathrm{~m} \\
\mathrm{~K}=51.9 \mathrm{~W} / \mathrm{m} . \mathrm{k} \text { (steel) } \\
\mathrm{T} 1=120^{\circ} \mathrm{C}-393 \mathrm{~K} \\
\mathrm{~T} 2=27^{\circ} \mathrm{C}-300 \mathrm{~K} \\
\mathrm{~A}=0.15 \mathrm{~m} \\
\dot{\mathrm{q}}=\frac{\mathrm{k} \cdot \mathrm{A}}{\mathrm{L}} \cdot\left(\mathrm{T}_{1}-\mathrm{T}_{2}\right) \Rightarrow \\
\mathrm{q}=\frac{51.9 \times 0.15}{0.002} \times(393-300) \\
\mathrm{q}=362002.5 \mathrm{Kcal} / \mathrm{h}
\end{gathered}
$$

To determine the amount of heat transferred from the box to the aluminum heads, an equation was used based on the Law of Thermodynamics, which is given by the following equation:

$$
\mathrm{Q}=\mathrm{m} * \mathrm{c} * \Delta \mathrm{t}
$$

Where Q represents the change in heat; $\mathrm{m}$ is the mass; $\mathrm{c}$ is the specific heat of the material and $\Delta \mathrm{T}$ is the temperature variation during the experiment. (Incropera, 2008).

Then we will show the calculation using Eq. (5), to determine the amount of heat transferred to the aluminum heads until reaching a temperature of $85^{\circ}$ $\mathrm{C}$, starting from an ambient temperature of $27^{\circ} \mathrm{C}$.

FINS (F)

$$
\begin{array}{ll}
\mathrm{M}=7389 \mathrm{~kg} & \mathrm{Q}=m^{*} c^{*} \Delta \mathrm{t} \\
\mathrm{C}=900 \mathrm{~J} / \mathrm{kgK} & \mathrm{Q}=7389 * 900 * 58 \\
\Delta \mathrm{t}=58 \mathrm{~K} & \mathrm{Q}=385.7 * 10^{6} \mathrm{~J}
\end{array}
$$

\section{NOT FINS (NF)}

$$
\begin{array}{ll}
\mathrm{M}=6287 \mathrm{~kg} & \mathrm{Q}=m^{*} c^{*} \Delta \mathrm{t} \\
\mathrm{C}=900 \mathrm{~J} / \mathrm{kgK} & \mathrm{Q}=6287 * 900 * 58 \\
\Delta \mathrm{t}=58 \mathrm{~K} & \mathrm{Q}=328.18 * 10^{6} \mathrm{~J}
\end{array}
$$

Next, the heating and cooling temperatures of the thermocouples that are in the same position (fins in BLUE and not fins in RED) will be presented. The data were taken from the table generated by the computer program.

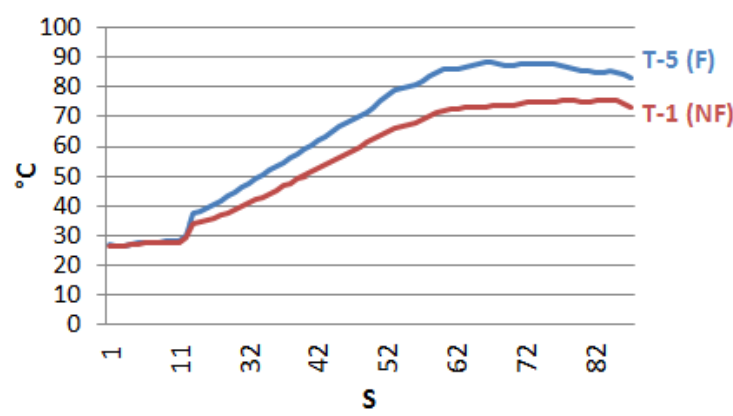

Graph 1. Heating Channel 1 and 5.

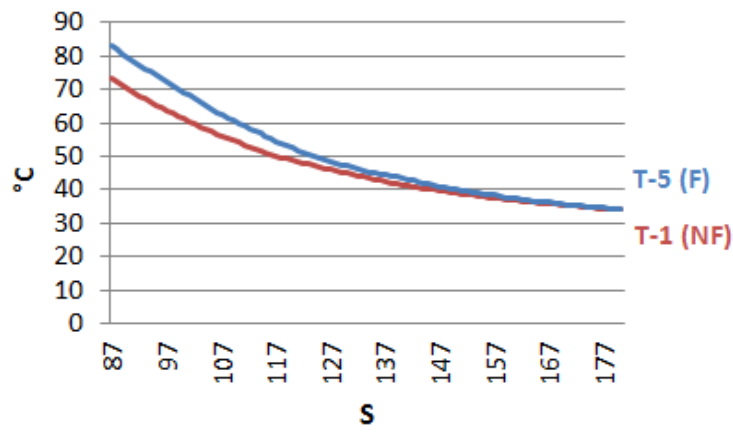

Graph 2. Cooling Channel 1 and 5. 


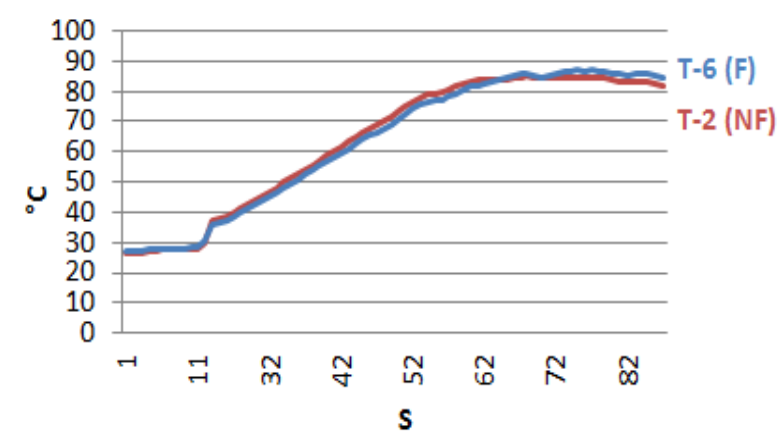

Graph 3. Heating Channel 2 and 6.

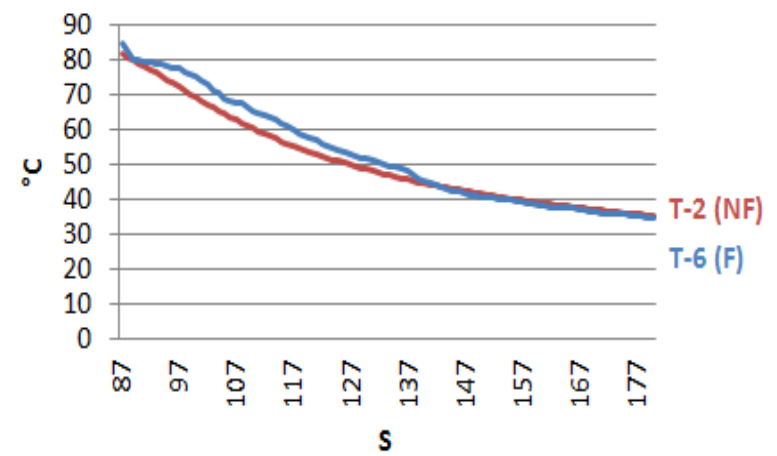

Graph 4. Cooling Channel 2 and 6.

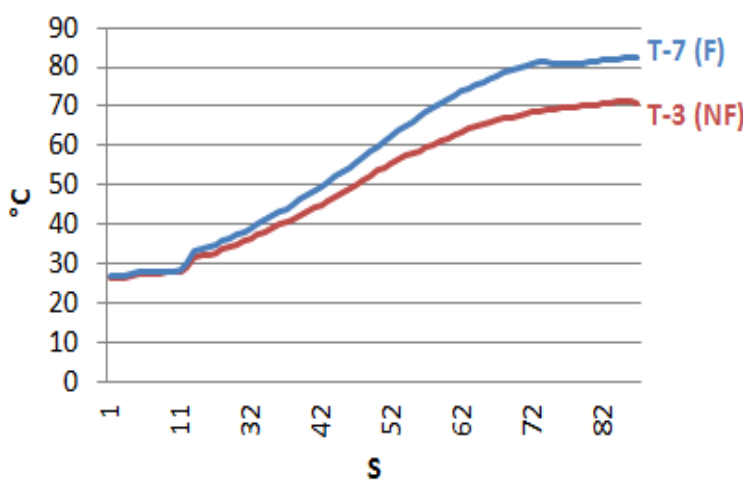

Graph 5. Heating Channel 3 and 7.

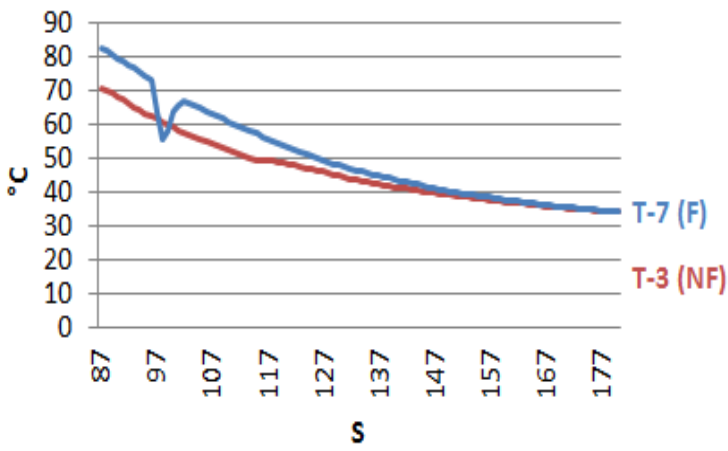

Graph 6. Cooling Channel 3 and 7.

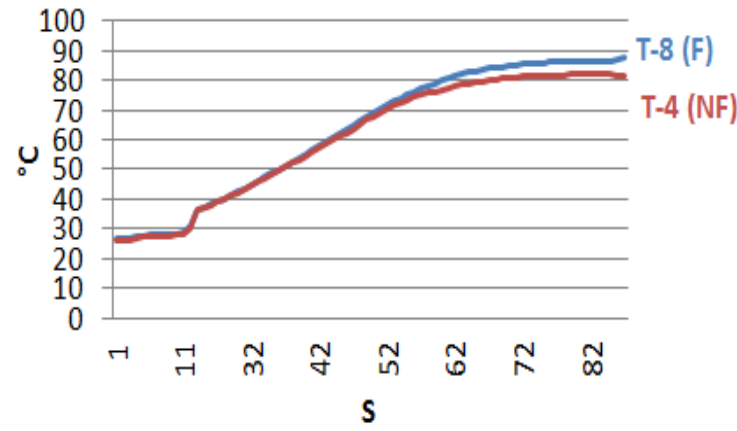

Graph 7. Heating Channel 4 and 8.

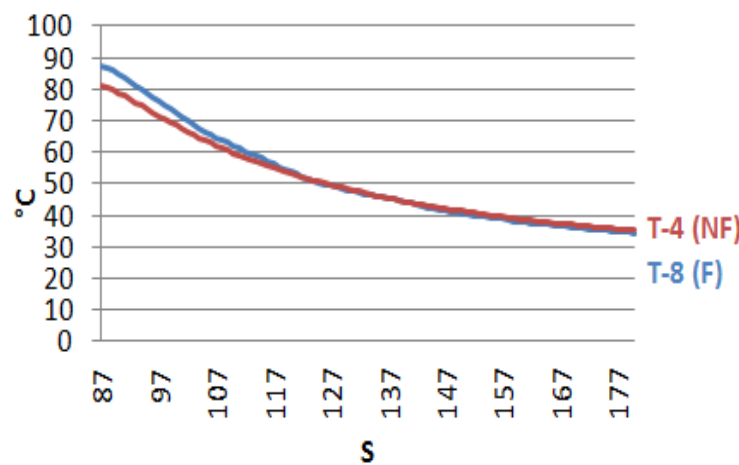

Graph 8. Cooling Channel 4 and 8.

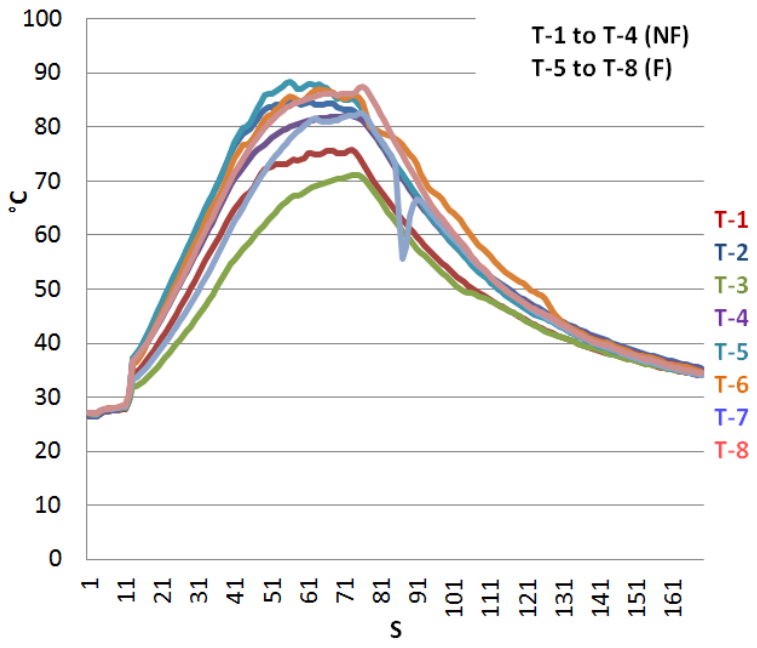

Graph 9. Comparison between all thermocouples.

The calculation of Thermal efficiency is obtained through the first Law of Thermodynamics, which is given by the equation:

$$
\text { EFFICIENCY }=\frac{Q 1-Q 2}{Q 1}
$$

Where Q1 is the final temperature and Q2 the initial temperature. 
For the calculation of the table below, Eq. (8) of thermal efficiency was used, where the initial and final temperature values of each channel were placed.

\begin{tabular}{|c|c|c|c|c|}
\hline \multirow{2}{*}{ CHANNEL } & $\mathbf{1}$ & $\mathbf{2}$ & $\mathbf{3}$ & $\mathbf{4}$ \\
\cline { 2 - 5 } & \multicolumn{5}{|c|}{ HEATING (\%) } \\
\hline NOT FINS & 63.81 & 67.42 & 62.60 & 67.49 \\
\hline FINS & 67.78 & 68.01 & 67.19 & 69.00 \\
\hline & \multicolumn{5}{|c|}{ COOLING (\%) } \\
\hline NOT FINS & 53.68 & 56.56 & 51.66 & 56.65 \\
\hline FINS & 59.02 & 58.91 & 58.63 & 60.65 \\
\hline
\end{tabular}

Table 1. Thermal Efficiency.

According to the data presented in the graphs and the thermal efficiency accounts above, we can visualize and prove the efficiency of the fin system that presented between the applied points a difference of 5 to $12 \%$ better than the non fin system.

\section{CONCLUSIONS}

Based on the experimental results, it was concluded that it was possible to compare the efficiency between finned and non-finned systems.

Among the results, the finned system presents higher efficiency, despite the variations between the verified points, in general it cools faster.

\section{ACKNOWLEDGEMENTS}

The authors thank the support of the Faculty Einstein de Limeira and the teachers involved.

\section{REFERENCES} Paulo.

Gaspar, A., 2002, Physics, Atica, Vol. 2, São

Kreith, F., 1969, Principles of Heat Transmission, Publisher Edgard Blücher LTDA., São Paulo.

Melo, L. F., 2013, Temperature Sensors: Thermocouples, State University of Londrina - UEL, Londrina-PR.

Souza, J. A. L., 2016, Heat Transfer, Pearson University Bibliography, São Paulo.

Incropera, Frank P., 2008, Fundamentals of Heat and Mass Transfer Sixth Edition, Rio de Janeiro. 